\title{
AS PARTEIRAS ERAM “TUTTE QUANTE” ITALIANAS (SÃO PAULO, 1870-1920)
}

\author{
The midwives were "tutte quante" Italian \\ (São Paulo, 1870-1920)
}

\begin{abstract}
Maria Lucia Mott*, Maria Aparecida Muniz*, Olga Sofia Fabergé Alves*, Ana Paula Ferreira Santos**, Karla Maestrini**, Tais dos Santos ${ }^{* *}$
\end{abstract}

\begin{abstract}
RESUMO
$\mathrm{O}$ artigo tem como tema as parteiras (italianas e brasileiras) diplomadas em diferentes cidades da Itália e em Innsbruck (Império Austro-Húngaro), que atuaram em São Paulo no período da imigração em massa de estrangeiros para o Brasil. Os objetivos são: 1) trazer para primeiro plano as parteiras estrangeiras diplomadas, cujo número não é desprezível face ao de brasileiras registradas no Serviço Sanitário; 2) problematizar a imagem da parteira imigrante, vista tradicionalmente pela historiografia como leiga, sem formação profissional ou qualificação técnica; 3) trazer elementos para repensar a participação das mulheres no espaço público na virada do século XIX para o XX, com destaque na área da Saúde; e 4) divulgar fontes pouco utilizadas pela historiografia da imigração, como os Livros de Registros da Fiscalização do Exercício Profissional, Atas, Livros de Exame de Habilitação, regulamentos e dossiês de alunas inscritas da Escola de Parteiras de São Paulo.
\end{abstract}

Palavras-chave: história dos trabalhadores da saúde; história da assistência ao parto; história da imigração italiana; gênero, memória e saúde.

\footnotetext{
ABSTRACT

The article focuses on the midwives (Italian and Brazilian) that graduated in Italian cities and in Innsbruck (Austro-Hungarian Empire) who worked in São Paulo during the period of Italian mass immigration to Brazil. The objectives are: 1 . To bring to light the role of foreign graduated midwives working mainly in the city of Sao Paulo, whose number couldn't be

* Instituto de Saúde/SESSP - e-mails: cucamott@uol.com.br, cidamuniz@isaude.sp.gov.br e

** PUCSP-e-mails: anapaula@benditazine.com.br, kakysnesquick@msn.com e tdsferreira@
} olga@isaude.sp.gov.br. yahoo.com.br. 
ignored if compared to the Brazilian registered midwives; 2 . To examine the immigrant midwife's image viewed traditionally by the historiography as untrained, ignorant and without professional or technical qualifications; 3. To rethink the women's participation in the public sphere at the end of the 19th and in the early 20th century and it's relation within the Health Services; 4.To utilize resources not always used in the historiography of immigration, such as the registers of inspection by the Health Service, minutes, registers of qualifications, regulations and dossiers of enrolled students at the Escola de Parteiras de São Paulo (Midwifery School).

Key words: history of the health workers; history of midwifery and childbirth; History of Italian Immigration; gender, memory and health.

\section{Apresentação***}

Quando tinha 30 e poucos anos, Francesca Mazzucchelli, filha de parteira, natural de Gallarate, Lombardia (Itália), deixou a aldeia e foi para Milão fazer um curso no Hospital Maior, com o professor Bernardino Moscati, aluno do famoso Levret ${ }^{1}$, onde depois de seis meses foi examinada e obteve diploma de parteira. De volta ao vilarejo, Francesca teve dificuldades em ganhar dinheiro e sustentar a família com a profissão devido à concorrência de duas parteiras leigas - as chamadas mammane (comadres ou curiosas em português). Em 1768, entrou com um recurso denunciando a situação. Os recursos impetrados por parteiras ocorreram na Itália desde meados do século XVIII, quando foram criadas as primeiras escolas para formação de levatrice. ${ }^{2}$

O uso de denúncia e de recursos legais para salvaguardar o exercício profissional não foi exclusivo das parteiras italianas. Atravessou o Atlântico, seguindo as diversas ondas de imigrantes que vieram para o Brasil. Há notícias sobre essas disputas entre parteiras de diferentes nacionalidades no Rio de Janeiro e em São Paulo, tanto na capital como no interior. ${ }^{3}$

*** Várias pessoas contribuíram para a realização desse trabalho com informações diversas, facilitando o acesso à documentação, bibliografia e tradução. A elas nossos agradecimentos: Ana Maria da Cunha, Barry Baker, Camila Silva Koenigstein, Cláudia Cristina dos Santos, Denis da Silva, Henriette Neirouz, José D. Najar, José Inácio de Melo Souza, MariaAntonietta C.S. Marcelli, Maria do Rosário R.R. Salles, Miridan Brito Knox Falcci, Mônica Schpun, Rute Castro, Uirá Knox Amaral, Yara Nogueira Monteiro, Yara Khouri, Yasser Aed El Fattah, Zuleika Alvim.

1 André Levret é considerado um dos mais famosos obstetras franceses do século XVIII, um dos grandes nomes dos estudos pélvicos. No seu livro $A$ arte dos partos demonstrada pelos princípios da Física e da Matemática, inclui minucioso estudo da bacia. Partidário das operações obstétricas, aperfeiçoou e divulgou o uso do fórceps. Atraiu alunos de várias partes da Europa, não só da Itália.

2 PANCINO, C. Il bambino e l'acqua sporca: storia della assistenza al parto dalle mammane alle ostetriche (secoli XV-XIX). Milano: Franco Angeli, 1984. p. 127.

3 Sobre recursos e disputas entre parteiras, ver também FILLIPINI, N. Levatrici e ostreticanti a Venezia tra Sette e Ottocento. Quaderni Storici, v. 58, n. 20(1), p.149-180, abr. 1985, e MOTT, M. L. Parteiras, o outro lado da profissão. Gênero, Revista de Estudos Transdisciplinar de Estudos de Gênero, v. 6 (1), p. 117-140, 2. sem. 2005. 
Inês Franschini, segundo ela mesma, revalidou o diploma de parteira pela Faculdade de Medicina do Rio de Janeiro e em 1918 se registrou no Serviço Sanitário do estado de São Paulo. No ofício, argumentava:

\begin{abstract}
Considerando que em Piracicaba existe uma senhora de nome Lucia de Mônica que exerce a obstetrícia e a especialização médica da ginecologia, abertamente como prova o próprio anúncio em jornal o que não compete se for parteira. Considerando constar que a mesma Senhora não tem diploma revalidado no Brasil ou registrado no Serviço Sanitário Estadual: Considerando, que assim for é ilegal o exercício profissional da mesma Senhora. É considerado que esta mesma senhora desta forma e com sua desleal concorrência prejudica os interessados, digo interesse da abaixo assinada, que escrupulosamente cumpre seus deveres profissionais. Venho pedir a V. Excia. se digne tomar as providências que o caso exige. ${ }^{4}$
\end{abstract}

A disputa profissional é apenas um dos aspectos poucos conhecidos sobre as parteiras que exerceram sua função em São Paulo no período de imigração em massa de italianos para o Brasil (1870-1920). A literatura médica do início do século XX, quando se refere a elas, em geral as desqualifica, como mulheres populares, ignorantes, sem conhecimento dos princípios de higiene (italianas de "dez filhos e unhas sujas"). ${ }^{5} \mathrm{~A}$ documentação produzida pelos representantes italianos encarregados da avaliação da situação dos imigrantes no estado de São Paulo se refere basicamente à assistência feita por parteiras leigas. ${ }^{6}$ A historiografia sobre imigração, seja ela rural ou voltada especificamente para os trabalhadores das cidades, os profissionais da saúde e as condições sanitárias do estado não as incluem ou não se detém sobre elas. ${ }^{7}$

4 Livro Serviço Sanitário 046/MO6, p. 45. Centro de Memória da Saúde/MEMO-SESSP)

5 AZEVEDO JR. Das comadres no Rio de Janeiro. Revista de Ginecologia e d'Obstetrícia, v. 1, n. 1-2, p. 279-281, jun. 1908.

6 "A assistência ao parto das parturientes, que, na maior parte dos casos, é feita por uma colona prática, a qual não observando qualquer regra não só de higiene, mas de limpeza ocasiona assim gravíssimas infecções puerperais, e não raro devido ao clima úmido, favorece a disseminação e a reprodução dos germes que causam a morte da puérpera e do recém-nascido.” TEDESCHI, U. Le condizione sanitarie a San Paolo (Brasile). Rapporto del vice-console (...). Roma: Tip. Nazionale di G. Bertero E. C., 1907.

7 A assistência ao parto das mulheres dos colonos também era problemática, pois o custo de uma parteira era igualmente elevado, aproximando-se do trabalho do médico (o procedimento custava 25 mil-réis), sendo o mais comum as vizinhas e os maridos auxiliarem no parto. A maioria dos nascimentos nas capitais e cidades do interior do Brasil acontecia com o auxílio de parteiras práticas, sem qualificação formal. Com isso, as complicações tornavam-se fatais, havendo muitas mortes perinatais. TELAROLLI JUNIOR, R. Imigração e epidemias no estado de São Paulo. História, Ciências, Saúde, Rio de Janeiro, v. 3, n. 2, p. 265-283, 1996. Ver: HUTTER, L. M. Imigração Italiana em São Paulo (1880-1889). São Paulo: IEB/ USP, 1972; CENNI, Franco. Italianos no Brasil. São Paulo: Martins, 1975; ALVIM, Zuleika. Brava gente: os italianos em S. Paulo (1870-1920). São Paulo, 1986; TRENTO, A. Do outro lado do Atlâtico. São Paulo: Nobel, 1988; SALLES, M. R. R. Médicos italianos em São Paulo, 1890-1930: um projeto de ascensão social. São Paulo: Sumaré/IDESP/FAPESP, 1997. 
A imagem da parteira italiana como sendo leiga, reprodutora de práticas tradicionais, foi freqüente também em outros países. ${ }^{8}$ Nos Estados Unidos, onde existe uma historiografia importante sobre o tema, Diane Vecchio destaca que esse perfil tradicional precisa passar por uma revisão. Num artigo, a autora ressalta que as parteiras que se estabeleceram em Milwakee nas primeiras décadas do século XX tinham formação acadêmica adquirida ainda na Itália. Diferentemente de outros pesquisadores, como Charlotte G. Borst, Vecchio considera o trabalho das parteiras italianas como profissional, devido à capacitação técnica, ao comprometimento e ao empenho - não vê como uma continuidade das atividades domésticas ou desenvolvidas para complemento da renda familiar. A assistência prestada muitas vezes suplantava as obrigações de esposa e mãe de família. ${ }^{9}$

Este artigo visa trazer para primeiro plano as parteiras brasileiras e italianas diplomadas em diferentes cidades da Itália e na cidade de Innsbruck, que atuaram no estado de São Paulo entre 1870 e 1920, com o objetivo de repensar o papel da Saúde, com a inserção das mulheres no espaço público no referido período, bem como as atividades desempenhadas pelas mulheres imigrantes urbanas. ${ }^{10} \mathrm{O}$ número de parteiras estrangeiras é expressivo entre as diplomadas que trabalharam no estado, porém pequeno face ao número de nascimentos. ${ }^{11}$ Trata-se de uma pesquisa em andamento que faz parte de um projeto mais amplo, voltado para a construção de um banco de dados e para a análise da formação e do perfil dos trabalhadores que atuaram nas diferentes áreas da Saúde em São Paulo. ${ }^{12}$

8 No sentido de ter aprendido o ofício na prática.

9 VECCHIO, D. Gender, Domestic values, and Italian Working Women in Milwakee: Immigrant Midwives and Businesswomen. In: GABACCIA, D.; IACOVETTA (Ed.). Women, Gender, and Transnational Lives. Italian Workers of the World. Toronto: University of Toronto Press, 2002. p. 160-188; BORST, G. Charlotte. Catching Babies. Cambridge: Harvard University Press, 1995.

10 Utilizamos a expressão parteira diplomada para aquelas que fizeram o curso de parto e para as parteiras práticas habilitadas ou licenciadas, que fizeram exame numa escola e obtiveram autorização para exercer a profissão. Incluímos Innsbruck por situar-se no Tirol, território que pertencia parte à Itália, parte ao Império Austro-Húngaro.

11 Segundo o Almanaque Laemmert, o número da população paulista em 1911 foi estimado em 3.500.000 habitantes, sendo que nesse ano foram registrados 117.097 nascidos vivos.

12 História dos Trabalhadores da Saúde em São Paulo (1892-1978), pesquisa baseada nos Livros de Registros da Fiscalização do Exercício Profissional, realizada pelo grupo de pesquisa Gênero, Memória e Saúde, do Núcleo de Memória da Saúde do Instituto de Saúde/SESSP. O primeiro contato com a documentação ocorreu em 1999-2000, por ocasião da bolsa de pós-doutorado de uma das autoras, Maria Lucia Mott, na Escola de Enfermagem da USP, sob supervisão da Profa. Dra. Maria Alice Tsunechiro, financiada pela FAPESP. 
Utilizamos neste artigo fontes nem sempre privilegiadas pelos estudos sobre imigração, como os Livros de Registros da Fiscalização do Exercício Profissional da antiga Inspetoria de Higiene (LRFEP), Atas, Livros de Exame de Habilitação, regulamentos e dossiês de alunas inscritas da Escola de Parteira de São Paulo (EPSP). ${ }^{13}$ Utilizamos também matérias e anúncios publicados nos jornais e almanaques. ${ }^{14}$

\section{São Paulo e a imigração italiana}

Na década de 1870, São Paulo era uma cidade pequena, com pouco mais de 20 mil habitantes. Os partos em geral eram feitos por parteiras práticas, que atendiam na casa da parturiente. Havia poucos hospitais e casas de saúde, a capital não possuía maternidade, nem escolas de medicina, farmácia, odontologia ou cursos para formação de parteiras ou de enfermeiros. As fazendas de café começavam a se expandir pela província e a ampliar o cultivo de seus frutos, tendo então sido iniciada a implantação do sistema ferroviário; a presença de imigrantes era reduzida e os almanaques traziam os primeiros anúncios de parteiras diplomadas com sobrenomes estrangeiros.

O aumento do número de parteiras estrangeiras coincide com o aumento da população e o início da imigração em massa no estado de São Paulo, sobretudo de origem italiana. Se entre 1885 e 1889 entraram no país, segundo alguns autores, cerca de 140 mil italianos, entre 1890 e 1900 o montante triplicou. ${ }^{15}$ Entre 1890 e 1891, o número de anúncios de parteiras no Almanaque Seckler para São Paulo salta de 4 para 14. Em 1896, das 16 parteiras que anunciaram, metade tinha sobrenome italiano.

A se julgar o número de imigrantes italianos vivendo no estado de São Paulo, de parteiras formadas e habilitadas na Itália, bem como o número de alunas italianas formadas pela Escola de Parteiras de São Paulo, pode-se dizer que o estado era considerado como um mercado de trabalho propício para o exercício profissional. Entre as 88 parteiras inscritas no Serviço Sanitário entre 1892 e 1919,

13 A documentação da EPSP encontra-se na Escola de Enfermagem da USP.

14 A pesquisa nos jornais italianos, como o Fanfulla, ainda não terminou; também não foram consultados de forma sistemática os relatórios de representantes das autoridades italianas (Bollettini dell'Emmigrazione).

15 Salvo engano de nossa parte, não localizamos na bibliografia e documentação consultada referências à proporção entre homens e mulheres emigrados da Itália para o Brasil. 
43 eram italianas ( 55 se acrescentarmos as que tinham sobrenome italiano), 17 brasileiras, 15 de outras nacionalidades e 1 que não foi possível identificar o país de origem ( $\mathrm{N}$ no gráfico). ${ }^{16}$

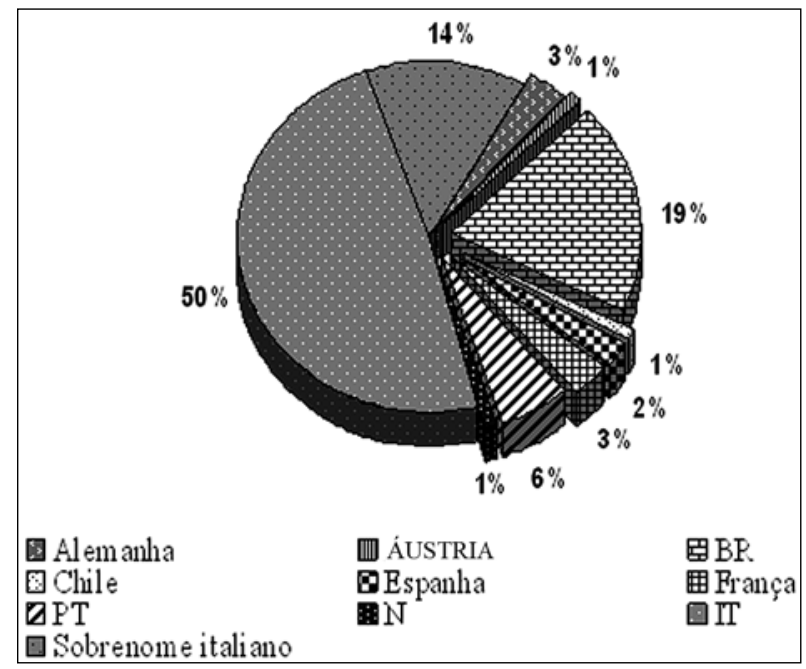

GRÁFICO 1 - PARTEIRAS REGISTRADAS EM SÃO PAULO SEGUNDO A NACIONALIDADE (1892-1919)

FONTE: LRFEP (1892-1919). MEMO

Projeto História dos Trabalhadores da Saúde em São Paulo (1892-1978)

A economia cafeeira impulsionou não só o crescimento demográfico, a criação da rede ferroviária, a imigração e a urbanização. Na virada do século, o estado se tornou um importante pólo comercial, bancário, industrial e também científico e cultural, inclusive com novas demandas na área da Saúde.

$\mathrm{Na}$ capital paulista e no interior, abriram-se escolas públicas e privadas - leigas e confessionais (católicas e protestantes) - algumas delas exclusivamente femininas, outras para os dois sexos, voltadas para o que hoje chamaríamos de Ensino Médio. A escola normal finalmente tomou corpo,

16 Nos primeiros anos, a EPSP teve grande contingente de alunas nascidas na Itália e de descendentes de italianos, somando mais da metade das alunas, entre 1912 e 1919. Angelina Cortese, nascida em Minas Gerais, obteve diploma em 1914; Narcisa Garofali Braga, natural de Mântua, se formou em 1915; Alba Campião di Stefano, de Pádua, em 1918. O tema será abordado posteriormente, em outro artigo. Arquivo Escola de Enfermagem da USP. 
revigorada, expandindo-se para diversas cidades do interior, e a capital deixou de ser burgo exclusivo dos estudantes da Faculdade de Direito. Os governantes, as elites e as camadas médias discutiam a criação de outras escolas para formação profissional, inclusive das mulheres. Em 1898 foi criada a Escola Livre de Farmácia, que a partir de 1902 passou também a formar dentistas e parteiras; em 1911, a Universidade "Livre" de São Paulo inaugurou uma série de cursos; e em 1913, começou a funcionar a Faculdade de Medicina e Cirurgia de São Paulo. ${ }^{17}$

Desde o final do Império, o governo da província e dos municípios e as elites vinham promovendo uma série de mudanças no que se refere à Saúde Pública e à assistência, que continuaram em movimento ascendente nas décadas seguintes. Foram implantados serviços para combater as epidemias, prestar socorros de urgência; foram adotadas novas práticas de saneamento (água e esgoto), de tratamento, de cura e de cuidados baseadas nos princípios da medicina científica; criados serviços para fiscalizar o exercício profissional e impedir o charlatanismo; foi feita uma ampla divulgação da importância dos cuidados com a Saúde da população para o desenvolvimento da nação.

Nos jornais e almanaques, acompanha-se a criação do Hospital de São Joaquim (1876), para a comunidade portuguesa; o novo Hospital da Santa Casa, que contava com médicos e cirurgiões de renome (1885); o Hospital Samaritano, cujo corpo de enfermeiras era composto por profissionais estrangeiras treinadas (1894); a Maternidade de São Paulo (1894), para atendimento às mães pobres; o Hospital de Isolamento (1880), com o objetivo de combater as doenças infectocontagiosas; o Hospital Colônia de Juquery, inaugurado em 1898 em substituição ao antigo Hospício Provisório de Alienados; o Desinfectório Central (1893), que atendia casos de doenças transmissíveis, promovia desinfecções e desinfestações de ruas e casas e era encarregado da remoção de doentes para o Hospital de Isolamento e de pessoas já mortas; e o Instituto Vacinogênico, responsável pela promoção da vacinação dos habitantes, e o Bacteriológico, voltado aos estudos das epidemias (ambos de1892); e o Instituto Soroterápico do Butantan (1901), responsável pela fabricação de soros e vacinas. ${ }^{18}$

17 Essa universidade era uma escola particular e funcionou entre 1911 e 1917.

18 Sobre Serviços de Saúde em São Paulo, ver CASTRO-SANTOS, L. A. A reforma sanitária pelo alto: o pioneirismo paulista no início do século XX. Dados: Revista de Ciências Sociais, IUPERJ, Rio de Janeiro, v. 36, n. 3, p. 361-392, 1993; RIBEIRO, M. A. R. História sem fim... inventário da saúde pública: São Paulo, 1880-1930. São Paulo: Editora Unesp, 1993; ANTUNES, J. L. F.; NASCIMENTO, C. B; NASSI, L. C.; PREGNOLATTO, N. P. (Org.). Instituto Adolfo Lutz: 100 anos do Laboratório de Saúde Pública. São Paulo: Letras \& Letras, 1992; e TELAROLLI JUNIOR, op. cit. 
Cresceu o número de farmácias, drogarias e laboratórios; dentistas, médicos e parteiras diplomadas se instalaram em diversas localidades do estado, sobretudo na capital.

\section{Formação e habilitação das parteiras italianas pós-unificação}

As escolas do norte da Itália forneceram o maior número de parteiras diplomadas para o estado de São Paulo, seguindo o perfil de imigrantes vindos no período: Vêneto, Emília-Romanha, Lombardia, Piemonte. Se por um lado corresponde ao perfil regional dos italianos que aqui entraram, por outro difere pelo fato de não serem "colonas", operárias, comerciantes, trabalhadoras de serviços informais e domésticos, artistas - mas mulheres alfabetizadas, profissionais liberais.

\section{TABELA 1 - PARTEIRAS ITALIANAS SEGUNDO ESCOLAS DE FORMAÇÃO/HABILITAÇÃO (1892-1919)}

\begin{tabular}{lll}
\hline PAÍ́S & ESCOLAS & TOTAL \\
\hline Itália & U. Pádua & 12 \\
& U. Bolonha & 4 \\
& U. Nápoles & 3 \\
& U. Parma & 3 \\
& U. Pavia & 3 \\
& U. Pisa & 3 \\
& U. Turim & 3 \\
& U. Gênova & 2 \\
& L. U. Urbino & 1 \\
& U. Ferrara & 1 \\
& U. Palermo & 1 \\
Império Austro-Húngaro & U. Innsbruck & 2 \\
\hline
\end{tabular}

FONTE: LRFEP (1892-1919). MEMO

Projeto História dos Trabalhadores da Saúde em São Paulo (1892-1978) 
Deve ser destacado que a formação de parteiras, sobretudo no norte da Itália, tem uma tradição secular. Desde o setecentos verifica-se a preocupação com a criação de escolas, o estabelecimento de hierarquias e a regulamentação das competências no exercício profissional na área da Saúde. As escolas inauguradas em diferentes reinos e estados ao longo do século XVIII tinham por objetivo o combate à mortalidade infantil, pois $\mathrm{o}$ aumento da população era tido como fator fundamental para riqueza e poder do Estado. ${ }^{19}$

Os cursos criados entre 1760 e 1870 tiveram trajetórias distintas, no que se refere ao funcionamento, às práticas e ao tipo de ensinamentos. $\mathrm{O}$ primeiro deles surgiu em Turim. Inicialmente eram privados, depois fundados ou incorporados pelos governantes ou autoridades municipais. Algumas escolas que estavam vinculadas a universidades, hospitais e maternidades tiveram possibilidade de oferecer ensino clínico; outras, pela falta de contato direto com a parturiente, faziam com que a formação clínica fosse substituída por ensinamentos feitos com manequins ou modelos de cerâmica. Outros cursos acabaram fechando ou funcionando de forma irregular. $\mathrm{O}$ número de parteiras instruídas por quase um século foi pequeno, não chegando a quebrar a hegemonia das antigas comadres na cena do parto, nem a alcançar a almejada queda da mortalidade de mães e recém-nascidos.

Nas últimas décadas do século XIX, ocorreram mudanças significavas no ensino, na prática e na legislação referente ao exercício profissional, quando da criação do Reino da Itália. O governo da unificação, desejando que as descobertas científicas das últimas décadas fossem incorporadas pelas parteiras, entre elas a assepsia, para o combate da febre puerperal, procurou intervir, estabelecendo novas regras. Aproveitando a experiência de algumas escolas que tinham sido bem-sucedidas, como aquelas localizadas na região Lombarda-Vêneta, regulamentou os cursos. As escolas deveriam estar anexas a universidades e hospitais ou maternidades. A grade curricular privilegiava o ensino teórico e prático, aprovada pelo Conselho

19 Este tópico, sobre formação das parteiras na Itália, baseou-se nos trabalhos de PANCINO, op. cit.; FILLIPINI, N. M. The Church, the State and childbirth in Italy. In: MARLAND, H. (Org.). The art of midwifery: early modern midwives in Europe. London: Routledge, 1993. p.152-175; GÉLIS, Jacques. Sage-femme ou médecin: une nouvelle conception de la vie. Paris, 1988, Fayard; GISSI, A. Parteiras e controle da natalidade na Europa do século XX. Gênero, Revista de Estudos Transdiciplinar de Estudos de Gênero, v. 6, n. 1, p. 11-43, 2. sem. 2005; GISSI, A. Between Tradition and Profession: Italian Midwives during the Fascist Period. In: WILLSON, P. Gender, Family and Sexuality. New York: Palgrave MacMilan, 2004. p. $122-138$. 
da Faculdade. O regulamento estabeleceu que o ensino restringia-se a alunas com idade entre 18 e 36 anos, tinha duração de dois anos, período durante o qual as futuras parteiras aprendiam a partejar, inclusive a fazer algumas operações, como a versão, e a usar instrumentos como o fórceps. Mas aprendiam, sobretudo, a respeitarem a hierarquia médica e a se tornarem grandes divulgadoras e promotoras dos princípios higiênicos e das novas práticas em torno do nascimento.

As parteiras eram responsáveis pelos partos normais, sendo obrigadas a chamar um médico em casos complicados. Na falta deste, deveriam fazer aquilo que fosse necessário, inclusive algumas operações. Eram responsáveis pela assistência das mulheres pobres, pelo combate à febre puerperal, pela denúncia às autoridades dos casos de febre alta, pelo registro dos nascidos vivos e nascidos mortos; e estavam sujeitas às penalidades em casos de aborto, troca de crianças, mudança no estado civil da mãe, entre outras ocorrências.

Ao lado da preocupação demográfica, um dos objetivos da criação de escolas era combater as parteiras leigas, impedindo-as de prestar os diferentes serviços que tradicionalmente faziam parte do ofício, como o controle da natalidade, substituindo-as por parteiras diplomadas treinadas por médicos. A proposta não teve condições de se efetivar de imediato, entre outros motivos pela falta de parteiras diplomadas em muitas localidades e a recusa da população em aceitar as novas profissionais: nas últimas décadas do século, o exercício das mamane foi legalizado desde que elas fizessem exame prático junto às escolas de parteiras. Essa legislação, que deveria ter caráter provisório, ficou em vigor por 34 anos e acabou gerando forte conflito entre as velhas e as novas parteiras. ${ }^{20}$

No final do século XIX, as parteiras diplomadas tinham dado um passo importante na profissionalização: estavam organizadas em associações, escreviam para revistas especializadas e discutiam sobre direitos trabalhistas e a necessidade de proibição do exercício das parteiras leigas. Isso não significou, porém, que tivessem incorporado por completo o modelo "oficial" de parteira, desejado pelas autoridades, e abandonado práticas, conhecimentos e serviços desempenhados pelas suas antepassadas, como por exemplo o tratamento ginecológico, o controle da natalidade, inclusive o aborto. Deve ser lembrado que, até a década de 1930 , cerca de $95 \%$ dos partos na Itália eram feitos por parteiras diplomadas e leigas. 


\section{Revalidando os diplomas}

As parteiras diplomadas na Itália que atuaram em São Paulo entre 1870 e 1920 pertenciam à geração pós-unificação. Algumas entre elas fizeram o curso e obtiveram diploma, como Maria Mastena Menini, que estudou na Universidade de Pádua e diplomou-se em 1877; outras obtiveram habilitação realizando o exame prático, como Theodolina Padovani, em 1894, na mesma universidade. ${ }^{21}$

Pelos registros, nem sempre é possível identificar quais entre as parteiras italianas freqüentaram o curso como alunas regulares e as que obtiveram habilitação por exame prático, o que inviabiliza uma avaliação quantitativa do dado. Importa, no entanto, destacar que para o Serviço Sanitário de São Paulo havia equiparação entre as que tinham obtido diploma depois da freqüência de um curso e as habilitadas - o que sugere que a institucionalização da obstetrícia ainda dava os primeiros passos.

A Lei n. 394, de 7/10/1896, que aprovava o Regulamento do Serviço Sanitário em São Paulo, estabelecia que só poderiam exercer as pessoas que se mostrassem habilitadas por título conferido ou reconhecido por qualquer das Faculdades de Medicina da República dos Estados Unidos do Brasil, e tivessem seus títulos registrados na diretoria do Serviço Sanitário. ${ }^{22}$ A legislação modificou-se poucos anos depois e regulamentou a habilitação e o registro de parteiras práticas, enquanto não houvesse curso de parteiras em São Paulo. ${ }^{23}$

Desde o Império, revalidar o diploma obtido no exterior não era tarefa fácil. Pelo fato de haver apenas duas escolas no Brasil, as candidatas residentes fora da Corte ou de Salvador eram obrigadas a se deslocar para uma dessas duas cidades. A questão da língua era outro problema. Na Faculdade de Medicina do Rio de Janeiro, os exames eram feitos em português ou francês. ${ }^{24}$ No final do século XIX, já durante o Período Republicano, a hegemonia das duas escolas médicas foi quebrada, foram abertos novos cursos no país, o que possibilitou que as candidatas revalidassem seus diplomas no estado onde iriam residir - caso houvesse uma escola reconhecida pelo governo.

21 LRFEP (1892-1919). MEMO.

22 SÃO PAULO. Coleção de Leis do Estado. Lei n. 394, de 7/10/1896. Aprova o Regulamento do Serviço Sanitário.

23 SÃO PAULO. Coleção de Leis. Lei n. 665, de 6/9/1899.

24 A parteira Cecília Jacobsen, formada pela Escola de Parteiras de Copenhague, não pôde se submeter ao exame, alegando que poderia responder as perguntas apenas em dinamarquês. (Arquivo Nacional IE3 - 102). Segundo M. R. R. SALLES, os exames dos médicos podiam ser em inglês, francês e latim (p.17). 
Em São Paulo, a Escola Livre de Farmácia foi a instituição responsável pela habilitação de parteiras práticas. As candidatas deveriam passar por exames escrito, oral e prática. Os pontos versavam sobre a anatomia da bacia e do aparelho genital da mulher, fisiologia da prenhez, patologia clínica e terapêutica obstétrica. Havia uma comissão examinadora, composta pelo diretor da Maternidade de São Paulo, três lentes da Escola Livre de Farmácia (formados em Medicina) e um fiscal do governo. As candidatas à habilitação deveriam apresentar: certificado de nascimento e de vacinação e comprovação de identidade e de idoneidade, além de pagar uma taxa exigida pela escola. ${ }^{25}$ Por sinal, todas as parteiras práticas examinadas pela referida escola tinham sobrenome italiano. ${ }^{26}$

Em 1902 foi criado um curso para formação de dentistas e parteiras na Escola Livre de Farmácia, que passou a se chamar Escola de Farmácia, Odontologia e Obstetrícia de São Paulo (EFOOSP). O curso, que funcionou até 1912, também habilitava parteiras estrangeiras. Das 11 parteiras que requereram revalidação, 8 eram italianas, 9 se considerarmos os sobrenomes italianos.

TABELA 2 - PARTEIRAS HABILITADAS PELA EFOOSP (1902-1912)

\begin{tabular}{llll}
\hline NOME & ESCOLA & ANO DIPLOMA & ANO REVALIDAÇÃO \\
\hline Augusta Mingarini & U. Bolonha & 1894 & 1905 \\
Dirce Zamboni & U. Pádua & 1896 & 1905 \\
Henriqueta Caniatti & U. Pádua & $\mathrm{N}$ & 1905 \\
Ida Rizzola & $\mathrm{N}$ & $\mathrm{N}$ & 1905 \\
Neglina Camparini & U. Parma & 1907 & 1908 \\
Elizabeta Maschietta & U. Pádua & 1894 & 1909 \\
Angeolina Segala & U. Pavia & $\mathrm{N}$ & 1911 \\
Guiglermina di & & & 1911 \\
Natale Alcotti & U. Parma & 1908 & 1911 \\
Arcangela Leonardi & U. Palermo & 1905 & \\
\hline
\end{tabular}

FONTE: Arquivo Faculdade de Odontologia USP - Livro n. 239

25 ESCOLA LIVRE DE FARMÁCIA. Revista Médica de São Paulo, v. 3, n. 5, p. 109-110, 15/5/1900. Ver: POURCHET-CAMPOS, M. A. A vida da Faculdade de Ciências Farmacêuticas da USP: notas históricas. São Paulo: FCFUSP, 1984; MOTT, M. L. As parteiras e a assistência ao parto em São Paulo nas primeiras décadas do século XX. Revista do Instituto Histórico e Geográfico de São Paulo, v. 163, n. 415, p. 67-84, abr./jun. 2002.

26 Eram elas: Antonia Nanni in Salini, Assunta Giusta (1902), Celeste Pavani Rizzoli, Constantina Rizzo (1902) e Rozário Giuseppilla (1902). Arquivo Faculdade de Odontologia USP, Livro n. 239. 
No mesmo ano de 1912 foi inaugurada a Escola de Parteiras na Maternidade de São Paulo (EPSP). Em 1915 o diretor da escola, o médico Sylvio Maya, enviou uma memória ao governo estadual solicitando o reconhecimento da nova instituição. Entre os motivos alegados, destacava:

[a Escola] é procurada por interessadas, que desejam exercer a profissão de parteira, incluídas nesse número não só aquelas que pretendem seguir um curso regular de Obstetrícia, como as parteiras diplomadas no estrangeiro que precisam para se habilitarem ao exercício da profissão no Estado, prestar prova de suficiência. ${ }^{27}$

O diretor informava que, em 1914 e 1915, procedeu 17 exames de habilitação, tendo reprovado cinco candidatas. Segundo o médico, apesar de prevista a cobrança de uma taxa para os referidos exames, tal não havia ocorrido de imediato pelo fato do curso até então não ter sido oficializado. Mesmo assim, dizia que o Serviço Sanitário do estado vinha aceitando o registro das parteiras habilitadas a título provisório e aguardava "confiante, o seu reconhecimento oficial pelo Governo do Estado"28.

O Regulamento da EPSP (1915) estabelecia que as profissionais diplomadas no estrangeiro que quisessem habilitar-se para exercer sua função no estado deveriam passar no exame das $1 .^{\mathrm{a}}$ e 2. ${ }^{\mathrm{a}}$ cadeiras do $2 .^{\circ}$ ano, ou seja, Clínica Obstétrica e Clínica Ginecológica. ${ }^{29}$ Para ser admitida ao exame de habilitação, a candidata deveria apresentar requerimento, diploma de parteira autenticado pelo representante do Brasil no país em que tivesse obtido e prova de identidade ${ }^{30}$, além de recibo de pagamento da taxa de exame. O custo de $500 \$ 000$ (quinhentos mil-réis) incluía exame e certificado, valor considerável se verificarmos que o aluguel mensal da escola era na época $150 \$ 000$ (cento e cinqüenta mil-réis) e o secretário da escola, Dr. Raul Briquet, recebia uma gratificação mensal de $100 \$ 000$

27 Ata da Escola de Parteiras (p. 4 e 5). Arquivo Escola de Enfermagem da USP.

28 Ibid., p. 8.

29 Não faz menção à proficiência em português ou outro idioma.

30 "Os imigrantes que possuíam atestados ou documentos estrangeiros precisavam, antes de partir da Europa, apresentá-los no Consulado Brasileiro para que os mesmos fossem visados, sem o que não teriam validade." HUTTER, op. cit., p. 60. 
(cem mil-réis) ${ }^{31}$ Esse também era o valor da multa cobrada por quem exercia sem diploma. ${ }^{32}$ Trabalhadores para serviços gerais ganhavam $3 \$ 000$ por dia, em 1913, segundo o Boletim do Departamento do Trabalho.

Entre 1914 e 1930, a EPSP recebeu requisição de 49 parteiras diplomadas no exterior, sendo que 5 delas nasceram no Brasil e se formaram fora do país. Entre as profissionais, 33 eram de naturalidade italiana. Entre 1914 e 1930, verifica-se um decréscimo no número de pedidos de revalidação de diplomas de parteiras diplomadas na Itália: entre 1914 e 1919, 74\% (20 das 27 solicitações); entre 1920 e 1925, 71\% (10 das 14 solicitações); e nos anos de 1926 a 1930, 37,5\% (3 das 8 solicitações).

As parteiras registradas no Serviço Sanitário e as habilitadas pela EPSP obtiveram em sua maioria diploma na Universidade de Pádua.

TABELA 3 - PARTEIRAS HABILITADAS PELA EPSP (1914-1930)

\begin{tabular}{lll}
\hline ESCOLAS & NATURALIDADE DA DIPLOMADA & TOTAL \\
\hline U. Pádua & Brasil/Itália & $12^{*}$ \\
U. Nápoles & Itália & 4 \\
U. Bolonha & Itália & 3 \\
U. Pavia & Itália & 3 \\
U. Turim & Itália & 3 \\
U. Ferrara & Itália & 2 \\
U. Parma & Itália & 2 \\
U. Pisa & Itália & 2 \\
U. Gênova & Brasil & 1 \\
U. Módena & Itália & 1 \\
U. Roma & Itália & 1 \\
\hline
\end{tabular}

* Duas brasileiras foram diplomadas pela Universidade de Pádua

FONTE: Livro de Habilitação EPSP - Arquivo Escola de Enfermagem da USP

31 Ata da Escola de Parteiras, p. 5 e 9. Arquivo Escola de Enfermagem da USP. SÃO PAULO. Coleção de Leis. Lei n. 432, de 3/8/1896, Artigo 97: A parteira que exercer a profissão sem título legal registrado na repartição competente será multada em cem mil-réis, como pagará igual quantia, ou será suspensa do exercício da profissão, por um ou três meses, segundo a gravidade do caso; Lei n. 1134, de 7/10/1908, Artigo 55: As infrações do disposto neste capítulo serão punidas do seguinte modo: $1^{\circ}$ Quem exercer a profissão de parteira, sem título legal, incorrerá na multa de $100 \$ 000$ e o dobro nas reincidências. $2^{\circ} \mathrm{A}$ parteira que exercer a sua profissão, sem ter o seu título registrado, incorrerá na multa de 100\$000; Lei n. 2140, de 7/11/1911; Lei n. 2140, de 7/11/1911, Decreto n. 2141, de 14/11/1911, Artigo 85: Para exercer a profissão, é a parteira obrigada a registrar o seu título na Diretoria Geral do Serviço Sanitário. Pena de multa de cem mil-réis.

32 SÃO PAULO. Coleção de Leis do Estado. Lei n. 1134, de 7/10/1908. Regula o exercício das profissões de farmacêutico, dentista e parteira. 
Os exames de habilitação, entre 1914 e 1930, eram feitos pelos professores da Escola de Parteiras, como Sylvio Maya, Raul Briquet, Viera Marcondes e Onofre Araújo. As notas para aprovação variavam entre 1 e 10. Margarida Girino, da província de Alessandria, formada pela Universidade de Turim em 1900, fez exame em 1914 e obteve a nota máxima. Nem todas as parteiras inscritas tiveram notas tão boas, e houve até algumas que foram reprovadas. A parteira Joana Frescura, diplomada pela Universidade de Pádua em 1883 e examinada em 1915 - o que poderia indicar muitos anos de prática -, apresentou-se três vezes, sendo aprovada somente na terceira, em 1916, com a nota mínima, nota $1 . .^{33}$

O Livro de Habilitação de Parteiras da EPSP não possibilita o uso de uma amostra estatística da idade das parteiras - no sentido de comparar com a data em que obtiveram o diploma e em que solicitaram a revalidação -, o que possibilitaria verificar se a prática anterior incidia positivamente na avaliação e/ou se os professores preferiam alunas mais jovens, com formação escolar, menos comprometidas com usos e costumes tradicionais. Entre os dados levantados, verificou-se que a maioria das alunas tinha entre 20 e 30 anos. Algumas jovens recém-formadas tiveram boas notas, e outras não. Um caso merece destaque, apesar de não dizer respeito às parteiras de nacionalidade italiana: Juliana Luiza Luiz, de origem húngara, diplomou-se pela Universidade de Viena com 36 anos e solicitou a revalidação aos 60 anos de vida, sendo aprovada com nota 10.

Vencida a etapa da revalidação, as parteiras deveriam inscreverse no Serviço Sanitário do estado. Só então estavam em condições de exercer a profissão segundo as normas vigentes no país.

Dadas as dificuldades e o custo para revalidação e registro de diplomas, muitas parteiras estrangeiras, de diferentes nacionalidades, acabaram não seguindo as regras, apesar das multas previstas. O jornal Fanfulla, da comunidade italiana de São Paulo, publicou em 9/6/1896 uma matéria informando que o Serviço Sanitário convidava as parteiras citadas a apresentarem o diploma às autoridades:

33 Livro de Habilitação EPSP. Arquivo Escola de Enfermagem da USP (30/1/1915; 19/5/1915 e $15 / 2 / 1916)$ 
Assunta Nina, abitante al largo Paysandu, 34; Lucia Cappini, rua Conselheiro Chryspiniano, 59; Giancristoforo, largo della Memoria, 3; Vedova de Barros, rua José Bonifácio, 33; Clorinda Viana [Fiano], rua Bocayuva, 26; Ursula Endrizzi, rua Boa Vista, 74; Oswald, ladeira Porto Geral, 74; Lusa Lombardi, rua Glycerio, 41; Rosa Capelli, rua Piratininga, 89; Adele Belloni, rua Nothmann; Maria da Silva, rua da Vitória, 52; Luisa Anot, rua Helvetia, 36; Maria Ferreira da Silva, rua S. João, 53; Betina, rua Ipiranga, 161; Rafaela, rua Major Diogo, 47; Peppina, rua Martinho Prado, 20; Palmira Copazzi, rua Santa Ephigenia, 182; Filomena Viola, rua do Gazômetro, 15; Ângela Silveri, rua do Gazômetro, 75; Joaquina Alvez Cruz, rua 25 de março, 189; Avenia Donnicher, rua dos Imigrantes, 116; Maria Antônia, rua Mooca, 60; Eugenia Hespanhola, rua Glycerio, 55; e Maria, rua dos Carmelitas, 29.

O Serviço de Fiscalização, embora tenha demonstrado em muitos momentos vontade política em controlar o exercício profissional, não foi efetivo. Parteiras estrangeiras e nacionais com ou sem diploma ou registro continuaram atuando, inclusive colaborando com médicos. Outras buscaram revalidar o diploma e inscreverem-se anos depois.

Ursula ou Orsula Endrizzi chegou a São Paulo com as primeiras levas da imigração em massa de italianos. Instalou-se na capital paulista no final da década de 1870 . Anunciou de forma seguida nos almanaques entre 1883 e 1891. Trabalhou para e com alguns dos principais médicos da cidade, entre eles Jaime Serva, Pereira Barreto, Guilherme Ellis, Caetano de Campos e Carlos Botelho. Em 23/1/1884, A Província de São Paulo trouxe uma carta respondendo a uma denúncia anônima de imperícia, publicada meses antes por um jornal. ${ }^{34} \mathrm{O}$ médico Mariano Joaquim da Costa Ferreira atestou que viu o diploma da parteira, obtido na Universidade de Innsbruck. Aconselhou-a a fazer o exame de habilitação, conselho que parece não ter seguido, pois seu nome está na lista dos profissionais que exerciam ilegalmente a profissão em 1887 e, ainda em 1896, conforme se viu, esta não tinha se registrado.

Já Clorinda Fiano (ou Fians, conforme outros documentos), depois da denúncia, buscou efetivar a revalidação do diploma na Faculdade de Medicina do Rio de Janeiro e inscrever-se no Serviço Sanitário (1897). A parteira era natural de Nápoles (1867). Pelas páginas do Fanfulla, informava que estava estabelecida na Rua Quintino Bocaiúva, 26, era diplomada pela

34 MOTT, op. cit. 
Universidade de Nápoles e tinha trabalhado no Hospital Gesù Maria daquela cidade, com o "ilustre Prof. Otaviano Morisano".

\section{Competências das parteiras}

As parteiras italianas se instalaram na capital e em algumas cidades paulistas, como Jaú, Ribeirão Preto, Limeira, Itararé e São José do Rio Pardo. ${ }^{35} \mathrm{Na}$ cidade de São Paulo, se estabeleceram no Centro, no Bairro da Luz, na Liberdade, nas proximidades de estações de ferro, em locais de muita circulação, onde havia farmácias, dentistas, médicos, hotéis, lojas e escolas. Algumas habitavam em bairros tipicamente italianos - Brás, Mooca, Bom Retiro, Bexiga.

Os documentos sugerem que algumas parteiras tinham um perfil social e técnico diferenciado. Numa nota sobre o nascimento da filha de um importante jornalista da comunidade italiana, ao lado dos pais e da criança há menção ao nome da "distinta parteira":

\footnotetext{
Nascita - Ieri sera la signora Anna Centola, consorte del nostro amico il signore Nicola Ancona Lopez, dette alla luce una bella bambina che è stata chiamata Anna Maria Brazilina. Assistette il parto, che fu felicissimo, la distinta levatrice la signora Clorinda Fiano. ${ }^{36}$
}

Em 9/10/1896, o Fanfulla publicou uma nota de "agradecimento", na qual um pai ressalta a gentileza e elegância no exercício profissional da parteira Senhora Filomena Giancristoforo, parteira laureada na Universidade de Nápoles, Buenos Aires e Nova York, que atendeu o parto da esposa. Leonor H. Ferroni, formada pela Universidade de Turim em 1911,

35 As informações sobre a atuação das parteiras no interior foram localizadas no Fanfulla e no Almanaque Laemmert. Em 1913, a parteira Elizabetta Machietto Finotto, segundo o periódico, atuava em Limeira. Seu registro foi considerado sem efeito oito dias após ter sido efetuado no Serviço Sanitário em 1909. Era diplomada pela Universidade de Pádua (1894) e habilitada em 1908 pela EPSP.

36 "Nascimento - ontem à noite a senhora Anna Centola, esposa do nosso amigo senhor Nicola Ancona Lopez, deu à luz uma bela menina, que recebeu o nome de Ana Maria Brazilina. Assistiu o parto, que foi felicíssimo, a distinta parteira a senhora Clorinda Fiano.” Fanfulla, São Paulo 9/10/1896. 
foi uma das quatro parteiras que participou do Primeiro Congresso Médico Paulista, de $1916 .^{37}$

No final do século XIX, Maria Bertelli coloca como título num classificado "Parteira italiana", o que pode ser lido como um atributo considerado então positivo. ${ }^{38} \mathrm{~A}$ clientela era composta por italianos. Porém, o atendimento não se restringia apenas aos oriundi, conforme os anúncios em "ítalo-português", português e em outros idiomas. Madame Theodolina Padovani dizia que era parteira de 1. classe, que curava qualquer moléstia uterina, "Aborti. Infecontidade". Recebia para tratamento em sua casa ou em domicílio, atendia chamado a qualquer hora. Rua do Hospício, n. $22 .{ }^{39}$ Irene Mantovani, que era laureada pela Faculdade de Medicina de Innsbruck, aprovada pela Faculdade de Medicina do Rio de Janeiro, tinha longa prática, falava bem italiano e português e atendia chamados a qualquer hora. ${ }^{40}$

Ana Contaldi, natural de Nápoles, nascida provavelmente em 1858, diplomada pela Universidade de Nápoles em 1896 e habilitada pela Faculdade de Medicina do Rio de Janeiro em 1899, anunciou em português e em francês, no Le Messager de Saint Paul de 26/4/1902. Em diferentes classificados, informava que recebia parturientes em pensão, atendia qualquer dia e hora, prestava serviços no interior e cobrava em conformidade com a condição da pessoa. ${ }^{41} \mathrm{~A}$ parteira também anunciou em português e, em árabe, no jornal sírio Al-Akfar de 19/2/1904.

Anúncio - Parteira autorizada pela lei.

Sra. Contaldi, conhecida pela comunidade síria, anuncia a todos que está de volta de sua viagem a Europa e esta pronta para prestar auxílio às gestantes e para cuidar de doenças de mulheres, utilizando nova prática de massagem durante suas consultas. Seu consultório, no Largo do Ouvidor, 7, esta aberto para consultas entre 13:00 e 15:00. Mme Anna Contaldi. Parteira. Recebe parturientes em pensão. Largo do Ouvidor, $7 .{ }^{42}$

37 Lista dos participantes. Annaes do Primeiro Congresso Médico Paulista. São Paulo, $O$ Estado de S. Paulo, 1917.

38 "Parteira italiana. Maria Bertelli, formada em Turim. Oferece seus serviços e responde por consultas sobre moléstias no útero." Diário Popular, São Paulo, 8/3/1892.

39 Diário Popular, São Paulo, 10/7/1895.

40 O Estado de São Paulo, 21/6/1915.

41 O Estado de São Paulo, 23/3/1900; O Comércio, São Paulo, 13/1/1902.

42 Para a tradução, contamos com a ajuda de Henriette Neirouz, Yara Khouri, Uirá K. Amaral e Yasser Aed El Fattah. 


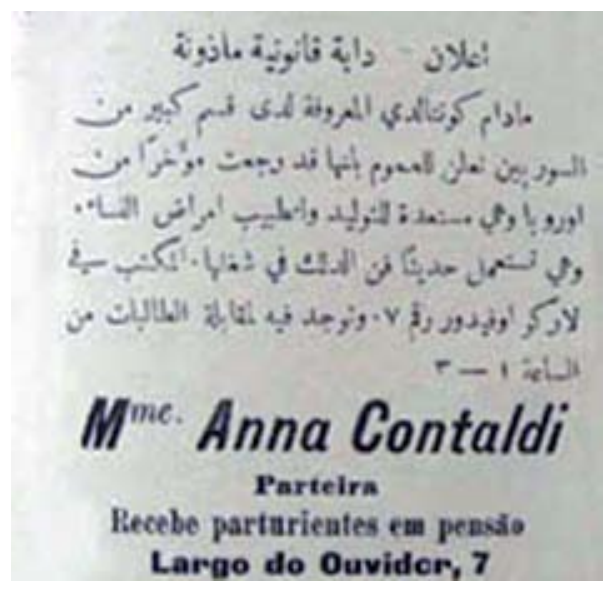

Al-Akfar, 19/2/1904

O registro profissional, a experiência, o exercício junto a médicos brasileiros e/ou italianos e o trabalho em hospitais e maternidades foram, sem dúvida, atributos considerados importantes para a obtenção da clientela e a criação de uma imagem de eficiência profissional. Algumas parteiras italianas se intitulam parteiras de 1 a classe, à semelhança das francesas, ou de "professoras", certamente para evidenciar que não eram parteiras práticas. ${ }^{43}$

Havia diferença na competência técnico-científica entre as parteiras diplomadas. Pela data de obtenção do diploma e de registro no Serviço Sanitário, verifica-se que houve parteiras que vieram com experiência profissional e outras sem. O tempo entre a obtenção de diploma e a revalidação de Joanna Frescura, formada pela U. Pádua, foi de 33 anos, conforme já mencionamos. Maria Bertelli diplomou-se, habilitou-se e registrou-se em poucos meses. ${ }^{44}$ Comparando-se, por sua vez, a data dos registros e dos anúncios, verifica-se que algumas parteiras italianas tiveram longa carreira no Brasil. Irene Mantovani, natural de Parma, formada pela Universidade de Innsbruck (1892), registrou-se no Serviço Sanitário em 1895 e, em 1928, ainda anunciava no Almanaque Laemmert.

43 MOTT, op. cit.

44 Diplomou-se pela U. Turim em 1891 e revalidou o diploma na Faculdade de Medicina do Rio de Janeiro em 1892, registrando-se no mesmo ano. 
Assim como outros profissionais da Saúde - médicos, dentistas e farmacêuticos -, as parteiras freqüentemente moravam e exerciam a profissão no mesmo endereço. Atuavam principalmente como profissionais liberais, atendendo no domicílio da cliente. Mais raramente, eram funcionárias de hospitais e maternidades. No final do século XIX e início do XX, a cidade de São Paulo possuía instituições que contratavam parteiras, como a Maternidade de São Paulo, a Hospedaria dos Imigrantes e a Santa Casa de Misericórdia, mas era um tipo de mercado de trabalho que começava a se desenvolver. Na Hospedaria dos Imigrantes, por sinal, trabalhava Rosalia Giambruno, que, segundo o livro comemorativo Il Brazile e gli italiani, publicado pelo jornal Fanfulla em 1906, tinha o cargo de "enfermeira" e, no Almanaque Laemmert de 1915, de "parteira". Deve ser mencionado que ela trabalhava num serviço público e não tinha registro no Serviço Sanitário do estado.

No que se refere aos serviços prestados pelas parteiras diplomadas, verifica-se que eram pontuais e diziam respeito a necessidades específicas, não se confundiam com serviços domésticos, como cozinhar e lavar a roupa da parturiente durante alguns dias, como parece ter sido usual entre as antigas comadres. Ou seja, os serviços eram da mesma natureza daqueles realizados pelas demais parteiras diplomadas que atuavam no período: faziam partos normais e dificultosos, determinavam a data provável do parto, davam banho e cuidavam do recém-nascido até a queda do cordão umbilical, socorriam os casos de infecção puerperal, cuidavam de abortos naturais e realizavam abortos, recebiam parturientes em suas casas, aplicavam injeções, eram chamadas como testemunhas em casos de infanticídio, passavam atestado de óbito em casos de inviabilidade do feto e tratavam das "doenças de senhoras", que pode ser lido também como um eufemismo nos anúncios para dizer que tratavam de doenças venéreas.

Quando achavam que era necessária e fosse possível, segundo as condições dadas, pediam a presença de um médico ou encaminhavam as parturientes para a Santa Casa ou para a Maternidade de São Paulo. Também, se chamadas, acompanhavam médicos em operações obstétricas e ginecológicas. ${ }^{45}$

45 O médico Luiz Pereira Barreto, ao referendar o trabalho de Ursula Endrizze, escreveu: "Tem trabalhado sobre minhas vistas em várias operações obstétricas e ginecológicas e posso garantir que conhece sua arte como qualquer outra diplomada, recomendando-se, além disto, pelo bom senso pouco vulgar, prudência e, sobretudo pelo total desprendimento do espírito de vaidade, habitual em suas colegas." (A Província de São Paulo, 23/1/1884). 
Muitas das atividades desenvolvidas pelas parteiras estavam proibidas pela legislação federal e estadual. A lei e a prática nem sempre andavam no mesmo sentido As parteiras fossem elas, brasileiras, italianas ou de qualquer nacionalidade, no exercício de sua profissão, frequentemente burlavam abertamente a legislação. Era-lhes proibido anunciar consultas, prescrever receitas ou aplicar quaisquer medicamentos que não fossem aconselhados na prática da assepsia obstétrica; praticar a ginecologia, fazer pequenas operações, e até mesmo curativos, sem orientação médica; praticar qualquer manobra em caso de distócia, salvo quando fosse impossível a presença de médico; receber parturientes ou gestantes em sua residência ou em outro local qualquer que tivesse caráter de maternidade ou enfermaria. ${ }^{46}$

\section{Aptidões e habilidades: Celeste Pavani e Natalina Rosati}

Na década de 1910, o jornal popular A Capital publicou algumas matérias referentes à atuação das parteiras italianas na cidade de São Paulo, que possibilitam analisar as práticas, os diferentes tipos de atividades, bem como as expectativas sobre as funções e as atribuições de parteiras e de médicos, as relações profissionais e sociais no período: enquanto a parteira Celeste Pavani é considerada porta-voz do discurso competente, a "famosa" Madame Natalina Rosati é execrada como "fazedora de anjos", "colonizadora do paraíso", "a megera horrenda cujo nome não é desconhecido dos cadastros policiais".

Em 14 e 15 de junho de 1915, saíram duas matérias sobre a morte de uma costureira, que teve assistência de Celeste Pavani, parteira habilitada pela Escola Livre de Farmácia e registrada desde 1902 no Serviço Sanitário. Segundo o jornal:

46 Entre 1890 e 1920, basicamente esse era o teor da legislação do estado de São Paulo sobre o exercício profissional. Ver leis e decretos: SÃO PAULO. Coleção de Leis do Estado. Lei n. 240, de 4/7/1893; Lei n. 394, de 7/10/1896; Lei n. 1134, de 7/10/1908; Decreto n. 2141, de 28/10/1911; e Decreto n. 2918 , de $9 / 4 / 1918$. 
Desde a idade de 17 anos que Celeste Pavani exerce a profissão de parteira. Diplomada na Itália, veio para São Paulo há mais de 15 anos. Aqui no nosso convívio, Celeste que vinha com o intuito de exercer a sua profissão, não demorou muito tempo e entrou para a Escola de Farmácia e depois de alguns anos de estudo e de prática, tirava um novo diploma, em abril de 1902. Diplomada também em São Paulo, Celeste cursou longo tempo na nossa maternidade. Depois de longa prática é que Celeste pôs em evidência o seu alto preparo teórico e prático. Com boa clientela, Pavani foi residir à Rua Benjamin de Oliveira, 77, estando aí morando até os tempos hodiernos. ${ }^{47}$

Para Celeste Pavani, o parto não era alarmante, não necessitava intervenção cirúrgica, nem seria necessária a intervenção médica, em vista "de o feto estar próximo e que a água do parto, estava quebrada, provando isso que depois de algumas horas, o pequenino ente apareceria". A família, inconformada com as dores da primípara Carolina - costureira "generosa" e virtuosa, filha de modestos italianos e casada com um motorista - contra a vontade da parteira, chamou o médico, também italiano, André Peggion, que "gozava de grande conceito científico" em São Paulo. ${ }^{48}$

O jornalista pergunta e responde qual seria a obrigação do médico logo ao chegar à cabeceira da enferma:

Era perguntar à parteira o estado da parturiente, assim pensamos nós. Pois Celeste Pavani ali estava e dias antecedentes, estivera tratando da infeliz Carolina. O cirurgião agiu de maneira bem contrária. Examinou a priori a doente e logo o fórceps foi introduzido na vagina da desventurada moçoila, trazendo o feto vivo. Usou, após esta rapidíssima operação, alguns anti-sépticos e para cortar a hemorragia que sobrevinha rápida injetou intramuscular uma injeção de Ergotina Dialezzata Zambetti (tipo Yvon). ${ }^{49}$

Depois do parto, segundo o jornal, Carolina teve febre alta, de 40 graus. Dr. Peggion foi, agora por insistência da parteira, chamado. Celeste Pavani teria recomendado que fossem convocados outros médicos e que a moça fosse levada para o "Sanatório" ou para a Maternidade. O médico respondeu: "Deixe que eu veja não se incomode."

47 A Capital, São Paulo, 14/6/1915.

48 Andrea Peggion, formado pela U. Pádua, solicitou o registro em 1903 no Serviço Sanitário (livro M01 - fls. 208). "É médico italiano, de corpo robusto, mediano, tem o seu consultório na Rua Florêncio de Abreu, 24a , é especialista (conforme seu anúncio) em vias geniturinárias, parto e sífilis." $A$ Capital, São Paulo, 15/6/1915.

49 A Capital, São Paulo, 15/6/1915. 
Nos dias seguintes, Carolina continuou com febre, o médico teria usado tintura de iodo, externa e internamente, o que a teria queimado. Ainda segundo A Capital, dados os sofrimentos, o patrão do marido o aconselhou levá-la para a Maternidade de São Paulo. Foi feita uma junta médica, da qual participaram os médicos Raul Briquet e Martins Passos, que declararam "que o caso era perdido". Carolina foi internada na Maternidade de São Paulo, vindo a falecer logo em seguida.

Os repórteres do jornal foram à residência de Celeste Pavani, situada na Rua Benjamin de Oliveira, 77, no bairro do Brás. A parteira é descrita com tendo estatura regular, magra. As matérias sugerem segurança no exercício profissional, responsabilidade e conflito em relação ao diagnóstico médico. Sugerem também que não existia identidade entre compatriotas, quando do exercício profissional - fossem eles médicos ou clientes:

- D. Celeste o parto de Carolina era laborioso?

- Não pelo contrário, o parto estava em excelentes condições, tanto que o dr. Peggion afirmou perante mim e as pessoas da família da doente, que não havia gravidade alguma.

- Mas a sra. acha que era necessária a aplicação do fórceps?

- Também não o feto estava na vagina e a sua cabeça já se apercebia.

- Há alguém que viu o feto nessas condições?

- A própria Magdalena [mãe de Carolina], pois, eu mesma lhe mostrei os cabelos do pequenino.

- Então pelo que vemos a senhora está desgostosa pelo desfecho cruel e inesperado da pobre Carolina?

- Perfeitamente, eu não queria o médico, falei categoricamente que o parto era ótimo e que as dores mostradas pela parturiente, eram devido a ser este o primeiro parto, e ele é sempre doloroso.

- ? ?

- Não vale à pena trabalhar com essa gente, perde-se o crédito, o tempo e o dinheiro...

- A morte de Carolina a senhora acha que foi casual ou por imperícia médica?

- Creio ser culpa do médico, pois a jovem não faleceria se estivesse nas minhas mãos. Em todo caso... a lei que faça a justiça...

[...]

- A senhora acha que Carolina Pecoraro faleceu em conseqüência de moléstia venérea?

- Não, mesmo porque eu tratei de uma mulher que, casando-se com um sifilítico, tornou-se sifilítica. Bem, depois de 9 meses, aparecia um recém nascido, sifilítico também.

- E o pequeno? 
- Vive, veio com o rosto e o corpo repletos de feridas...

- Então?

- Por esse motivo acho que Carolina não morreria. ${ }^{50}$

A reportagem informa que os jornalistas foram ouvir o Dr. Peggion. O médico "disse à família, ser a morte de Carolina proveniente da transmissão de uma moléstia venérea, que Domingos introduziu em sua mulher”. Ouviu também Dr. Raul Briquet, que confirmou o diagnóstico do médico, afirmando

por ser um caso muito raro, o Dr. Peggion merece-nos toda consideração e eu estou pronto para atestar a sua competência profissional [...]. Acho, porque os gonococos tomam proporções assustadoras no organismo humano. É o que não estamos autorizados a dizer. ${ }^{51}$

Os jornalistas duvidam do diagnóstico dos médicos, acatando o da parteira. Finalizando, a matéria publicou a foto do recém-nascido: "Cremos não ser possível que uma moléstia venérea devastasse o organismo resistente e forte de uma jovem, na plenitude do fulgor de seus anos, para deixar intacto o do pequenino." 52

Conforme foi dito, apesar de ser proibido pela legislação brasileira o tratamento de doenças de senhoras e o aborto, essas práticas continuavam a fazer parte dos serviços prestados pelas parteiras que atuavam em São Paulo, fossem elas italianas formadas na Itália, como Natalina Rosati, ou formadas pela Escola de Parteiras de São Paulo, como Teresa della Vecchia. ${ }^{53}$

Pelos Livros de Registro do Serviço Sanitário, notamos que Natalina Rosati foi a quarta parteira italiana a se registrar em São Paulo (e a sexta profissional pela ordem de inscrição). Obteve o diploma em 1883 pela Universidade Livre de Urbino, habilitou-se na Faculdade de Medicina do

50 A Capital, São Paulo, 15/6/1915.

$51 \quad I d$.

$52 I d$.

53 A Capital, São Paulo, 23/4/1923. Teresa della Vecchia, que foi "fotografada e recolhida à prisão", acusada de praticar aborto num hotel na cidade de São Paulo, na menor B. G., proveniente de Itu. Teresa era vêneta (de Schio), órfã, foi aluna interna do famoso colégio de freiras Patrocínio, de Itu. Formou-se em 1916, com 27 anos. 
Rio de Janeiro em 1892, tendo efetuado o registro no mesmo ano. ${ }^{54}$

A parteira, com freqüência, anunciava seus serviços em almanaques e jornais, em português e italiano, como no Fanfulla, no $O$ Estado de S. Paulo, no Diário Popular - apresentando-se como parteira "de primeira classe formada pela Universidade de Roma e do Rio de Janeiro". Assim como na trajetória educacional de Celeste Pavani, os dados levantados nos Livros de Registro do Serviço Sanitário e na imprensa não coincidem.

Em 1902, Natalina dizia que tinha 26 anos de prática e morava há 12 anos em São Paulo. ${ }^{55}$ Pelas informações fornecidas por ela mesma, pode-se dizer que teria atuado sete anos na Itália como mamana, antes de fazer o curso e obter diploma.

A parteira recebia parturientes e mulheres doentes para tratamento em sua "grande, arejada e higiênica casa", fazia partos simples e as "mais difíceis operações" em qualquer tipo de apresentação do feto, sabia tratar de hemorragias, extrair urina da bexiga, tinha "sangue frio", bem como outras especialidades:

A parteira Natalina Rosati comunica à sua numerosa freguesia que de volta da sua viagem estabeleceu provisoriamente sua residência na Rua Dutra Rodrigues n. 20, primeira travessa da São Caetano. Atende qualquer hora do dia e da noite. Especialidade casos de aborto. Para pobres $20 \$ 000 .^{56}$

A menção ao aborto pode ser lida como se ela tratasse casos de abortos espontâneos, prática usual entre as parteiras. Porém, pode ser lida também como se fizesse aborto. Em 16/7/1902, o jornal O Estado de S. Paulo publicou uma carta, que parece ter um duplo sentido: não só o de limpar o nome, agradecer ao advogado, mas o de divulgar que fazia abortos com segurança e sem riscos:

54 Em nome de Umberto I. Pela graça de Deus e pela vontade da Nação Rei da Itália. Nós professores, "Vincenzo Dottore Vanni", Regente da "Libera Universitá Provinciale degli studi di Urbino". Visto o atestado final dos estudos realizados e dos exames finais sustentados pela Senhora Natalina Rosati in Lippi [sobrenome do marido] di Jesi Província de Ancona foi-lhe passado o presente sob o número 369. Nós lhe conferimos o diploma de livre exercício em Obstetrícia. Dado nessa "Libera Universitá di Urbino", em 21/1/1886. LRFEP (1892-1906), p. 13.

55 O Estado de São Paulo, 22/2/1902.

56 Diário Popular, São Paulo, 22/3/1897. 
Após tantos sofrimentos e vexames por que passei em virtude de falsa denúncia de aborto por desafetos meus chegou-me enfim a ocasião de patentear ao público que o processo crime contra mim instaurado onde se imputava a prática de aborto criminoso por método especial baqueou ante a verdade apurada no sumário ex-ofício, a que respondi. É com sumo prazer que transcrevo despacho de não pronuncia proferido pelo íntegro e reto magistrado Dr. Augusto Meirelles Reis [...] Vê, portanto o público que as torpes acusações que se me ergueram caíram todas quer na egrégia câmara criminal, onde fui solta por hábeas corpus, quer perante o incorruptível juiz da vara criminal. Cumpre-me dizer que há muito já perdoei os meus acusadores gratuitos que desapiedosamente me caluniaram nos seus depoimentos! [...] Que o público agora me julgue se por ventura ainda não tenha me julgado. A justiça pode tardar, mas é infalível porque ela é emanação de Deus. São Paulo, 15/7/1902. Natalina Rosati. R Florêncio Abreu, 106.

Conforme mencionado em outro artigo, dez anos depois, em 1913, a parteira voltou às páginas dos jornais como personagem de um evento policial, referente a um caso de sedução e aborto. ${ }^{57}$ Um professor da Escola Normal, casado e pai de família, foi acusado de engravidar uma aluna, hospedada em sua casa como pensionista. A parteira, que morava então na Rua Florêncio de Abreu, 86, descrita como uma senhora gorda e baixa, era acusada de ter provocado aborto na jovem Alexandrina. O caso foi noticiado por dias seguidos no mês de julho até o início de agosto, nas primeiras páginas do jornal A Capital, com o título "O herói de Molière".

As reportagens foram documentadas com depoimentos e, em alguns números, ilustradas com caricaturas, que a aproximam da imagem que se tem de bruxa. Os jornalistas utilizaram títulos chamativos e até mesmo espirituosos (ora faziam trocadilho com o nome de Natalina-Matalina, ora a denominavam de "a colonizadora do paraíso", "ogra com pêlos nas ventas"), o que acabou vendendo edições extras do jornal.

As matérias informam sobre os diferentes profissionais que praticavam aborto (parteiras e farmacêuticos), os métodos utilizados (medicamentosos e cirúrgicos) e o preço cobrado.

Natalina provocava aborto com um longo estilete de aço, que era introduzido na vagina e perfurava no útero "o invólucro com que se gera o feto". O processo, descrito "como do mais negro e baixo charlatanismo", produzia hemorragia e dores fortíssimas. Se a paciente não morria, estava 
"salva... sem o filho". Segundo o repórter, essa era a segunda gravidez de Alexandrina. Na primeira, produtos vendidos por um farmacêutico foram utilizados com sucesso; na segunda não fizeram efeito, daí ter recorrido à parteira.

O aborto foi provocado aos quatro meses de gestação e custou $280 \$ 000$ (200\$000 pelo aborto e o restante pela “pensão"). Ou seja, cada aborto correspondia ao preço de cerca de 10 partos; ou dois abortos poderiam pagar um exame de revalidação de diploma estrangeiro. Certamente era um bom negócio! ${ }^{58}$

Segundo os jornalistas, ao ser convocada para depor, Natalina ameaçou fazer "revelações sensacionais contra as famílias de São Paulo, caso persistissem no intento de processá-la". Não sabemos se ela chegou a tanto. O jornal $A$ Capital foi informado de que ela teria provocado aborto não apenas em moças solteiras seduzidas e em prostitutas, como também em esposas e mães de família, e que Natalina reconstruía a virgindade, por um processo "infalível". 59

Dois casos foram publicados em 22/7/1913 pelo jornal. Uma "senhorita" informou que sua mãe "fora operada há poucos meses pela parteira sofrendo punções, abortando e vindo a falecer pouco depois"; além disso, revelou que a parteira enterrava os fetos no quintal da antiga residência na Rua Florêncio de Abreu. O outro caso diz respeito à "senhora de um açougueiro do Mercado Grande, à rua 25 de março e residente na Vila Maluf", que morreu quatro dias depois de "obter a provocação do aborto por Mme Matalina".

Segundo o jornal, foi feita uma investigação policial na casa da parteira na Rua Florêncio de Abreu, cujo resultado não foi comunicado à imprensa. ${ }^{60}$ "Sabemos, porém que foram ótimos." A fonte não fornece as evidências, mas sugere que a polícia encontrou provas contra Natalina.

Os jornalistas pedem a punição da "sinistra caranguejeira [...] para desagravo da sociedade paulista". Tanto ela quanto o professor fogem. Em

58 O preço do parto não é uma informação fácil de ser recuperada, visto ser cobrado segundo as condições sociais da parturiente atendida. Em 1897 Natalina informava que cobrava $20 \$ 000$ para os pobres. Houve pequena variação na taxa de inflação entre 1897 e 1915. Ver: EARP, F. S. Um século de inflação: a evidência empírica. Disponível em: <http://www.ufrgs.br/fce/rae/edicoes>. Acesso em: 22/1/1999.

59 Sobre reconstituição da virgindade pelas parteiras, ver: BRANDÃO, N. B. Da tesoura ao bisturi, o oficio das parteiras (1897-1967). Dissertação (Mestrado) - Instituto de Filosofia e Ciências Humanas, PUCRS.

60 A Capital, São Paulo, 19/7/1913. 
30/7/1913, o jornal A Capital informava aos leitores que não era conhecido o paradeiro da parteira. Especulava que talvez tivesse ido para a Europa, o Paraná ou Buenos Aires, e comenta sobre uma procuração transmitida para seus advogados sobre a condução do caso e execução de leilão de seus objetos, os quais o jornal qualifica como "velhos trastes entre os quais alguns estiletes enferrujados".

No dia seguinte, o jornal protestou contra a falta de energia da polícia, expressando sua indignação da seguinte forma:

Se esta mulher devia ser expulsa do território nacional, não na deviam ter deixado tempo suficiente para seguir viagem livremente. Urgia que fosse processada, que o seu nome e os seus crimes viessem à luz do dia, e fossem execrados pela opinião pública. Então sim a mandassem embora, escorraçada pela lei. Mas protegê-la, auxiliá-la na fuga isso não! Isso é vergonhoso, nos degrada.

A expulsão do país não aconteceu. Alguns meses depois ela voltou ao Brasil, sendo presa, conforme matéria publicada em $O$ Estado de $S$. Paulo de 27/3/1914.

Um agente do Dr. Franklin Piza, quarto delegado auxiliar, em obediência a ordens superiores, foi anteontem em diligencia policial a uma casa da vila Sá Barbosa, onde se achava a célebre parteira Natalina Rosati, efetuando sua prisão inclusa no artigo 301 do Código Penal. Natalina depois que soube que o juízo criminal contra ela decretara prisão preventiva escaparase para Buenos Aires, onde por algum tempo e com o nome de Ignácia Lippi, regressando há poucos dias a São Paulo, indo refugiar-se na casa, onde veio a ser presa. Essa parteira deu ontem entrada na cadeia pública onde aguardará o dia do seu julgamento.

Como verdadeira fênix, alguns anos mais tarde, Natalina voltou à ativa, anunciando seus serviços, nome, endereço e telefone. Em 1919 e 1920, localizamos novamente nos classificados de $O$ Estado de S. Paulo (21/12/1919 e 5/1/1920): "Formada Maternidade de Roma e do Rio de Janeiro e com diploma de Buenos Aires, avisa que se achando já restabelecida atende chamadas e cura doenças uterinas." 


\section{Considerações finais}

Não foi preciso procurar as parteiras diplomadas como "agulha no palheiro". Foram muitas as evidências encontradas, o que sugere que faziam parte ativa do cotidiano de São Paulo. Deve ser ressaltado que elas não foram as únicas, nem as que em maior número exerceram essa função no estado. Na década de 1930, o médico Edgard Braga, chefe do Serviço de Pré-Natal da Inspetoria de Higiene e Assistência à Infância em São Paulo, verificou a partir de pesquisa feita em 18 mil fichas de gestantes atendidas pelo serviço na capital, no decorrer de oito anos, que $85 \%$ das parturientes foram atendidas por parteiras leigas, $10 \%$ por parteiras diplomadas e $5 \%$ em hospitais e maternidades. ${ }^{61}$

Parteiras diplomadas com carreira longa e de sucesso e parteiras leigas, com diferentes tipos de qualificação, experiência e conhecimentos (ou não) das regras de assepsia, exercendo na legalidade ou na "clandestinamente", conviveram no mesmo período. Não há equívoco na afirmação de alguns autores que a assistência ao parto das mulheres imigrantes era feita por parteiras leigas, muitas delas com pouca experiência, que desconheciam as regras de higiene e as causas da transmissão das doenças. Em 1930, o Inspetor Chefe do Serviço Sanitário solicitava a internação de M.C., italiana, que vivia no Brasil desde os nove anos de idade, moradora do Bom Retiro e que exercia a profissão de parteira "apesar de ser leprosa". A Inspetoria a teria intimado várias vezes, aberto inquérito, impedindo que exercesse a obstetrícia e fosse internada, o que parece não ter ocorrido de imediato. No Inquérito Epidemiológico, M.C. negou qualquer contato com outros doentes "a não ser ter auxiliado como parteira prática de um médico doente em dois partos há 13 anos" ${ }^{\prime 62}$.

Porém, o grupo de parteiras diplomadas, bem como outras trabalhadoras da área da Saúde de origem italiana que prestaram serviços para a população, composto por mulheres alfabetizadas, independentes, que tinham grande mobilidade, qualificação profissional e voz própria, não

61 A clientela era composta por esposas de operários, auxiliares de comércio, funcionários públicos, militares, pequenos comerciantes e corretores. BRAGA, E. Da assistência ao parto nas maternidades. Revista de Ginecologia e d'Obstetrícia, v. 31, n. 5, p. 290 . maio 1937.

62 Prontuário 979. MEMO. 
pode ser esquecido, pois enriquece o conhecimento histórico. ${ }^{63}$ Ao levantar novas questões, amplia de modo significativo o leque de perfis de mulheres imigrantes e torna visíveis profissionais que atuaram em serviços cujo significado e importância não eram percebidos, isso até bem recentemente.

Para terminar, gostaríamos de nos reportar a uma observação de Zuleika Alvim, em Brava Gente! Diz a autora que a história dos italianos no Brasil "divide-se em dois momentos: antes e depois de emigrar" ${ }^{64}$. Traduzindo para o caso das parteiras, a citação nos lembra que as levatrici tinham uma história pregressa. Essa história - por que vieram, por onde andaram, o que teria motivado a viagem, se vieram sós, em busca de uma vida melhor, mais liberdade, com a esperança de "fazer a América" e retornar - é um capítulo que ainda não conseguimos escrever.

63 Nesse grupo poderiam ser incluídas outras profissionais, como Olga Caporali, nascida em Casalromano (1888), na Lombardia, formada em $1911 \mathrm{em} \mathrm{Medicina} \mathrm{pela} \mathrm{Universidade} \mathrm{de} \mathrm{Turim} \mathrm{e}$ registrada no Serviço Sanitário em 1915; ou a "Doctoressa" Camille Chiaves, ex-assistente do Laboratório Clínico de Bolonha, diretora do Laboratório Bacteriológico do Hospital Humberto Primo, estabelecida na Av. Anhangabaú, onde fazia diferentes tipos de análise laboratorial. (Fanfulla, São Paulo, 17/3/1913).

64 ALVIM, op. cit., p. 11. 